\title{
Correction to: Molecular mechanisms of mechanical load-induced osteoarthritis
}

\author{
Tianshun Fang ${ }^{1} \cdot$ Xianhao Zhou $^{1} \cdot$ Mingchao Jin $^{1} \cdot$ Jiangbo Nie ${ }^{1} \cdot{\text { Xlongfeng } \mathrm{Li}^{1}}^{1}$
}

Published online: 24 April 2021

(c) SICOT aisbl 2021

\section{Correction to: International Orthopaedics} https://doi.org/10.1007/s00264-021-04938-1

The article "Molecular mechanisms of mechanical loadinduced osteoarthritis", written by Tianshun Fang, Xianhao Zhou, Mingchao Jin, Jiangbo Nieand XIongfeng Li, was originally published electronically on the publisher's internet portal (currently SpringerLink) on January 2021 with open access.

With the author(s)' decision to step back from Open Choice, the copyright of the article was changed on April 2021 to (C) SICOT aisbl 2021 and the article is forthwith distributed under the terms of copyright.

The original article has been corrected.

The original article can be found online at https://doi.org/10.1007/ s00264-021-04938-1.

XIongfeng Li

2522892283@qq.com

1 Huzhou Central Hospital, 313000 Huzhou,

People's Republic of China 